\title{
Application of Hand Towel Drape over Dingman Mouth Gag
}

\section{Kyeong Beom Choi, Myong Chul Park}

Department of Plastic and Reconstructive Surgery, Ajou University Hospital, Ajou University School of Medicine, Suwon, Korea

No potential conflict of interest relevant to this article was reported.
In cleft palate surgery, the environment is especially critical when suturing. Encum-bered, obstructive space in the environment can hinder a suture while using the Dingman mouth gag. We introduced a novel but simple draping technique. A simple hand towel is placed over the gag. A hole is cut out in the middle according to each patient's mouth. After making the hole, the hand towel is soaked in water and gently squeezed. Then the towel is properly placed over the Dingman mouth gag. Dripping water on the hand towel during the suture helps keep it in place. Using this draping technique, we cut 14 minutes of operation time compared to the average operation time of the past 2 years. There were several disadvantages in previous draping method. First, long suture material may easily get caught. Second, the operation field can easily be contaminated. Third, focusing on the operation becomes difficult due to the obstruction. This draping technique can compensate for the disadvantages of the previous Dingman mouth gag.

Keywords: Cleft palate / Surgical drape / Suture / Oral surgical procedure

\section{INTRODUCTION}

In cleft surgery, there has been significant progress in repair technique. However, the surgical site environment has not kept up with this technical progress. This gap between technique and the environment has a significant impact on efficiency. A suturing environment with the Dingman mouth gag can be obstructive and inconvenient. Many cleft surgeons have had no choice but to work with this inconvenience.

\section{IDEA}

We introduced a simple but effective drape method for cleft palate surgery. The concept is quite simple. Patients were draped in the usual manner. When the flap dissection was over and the repair

\section{Correspondence: Myong Chul Park}

Department of Plastic and Reconstructive Surgery, Ajou University Hospital, Ajou University School of Medicine, 164 Worldcup-ro, Yeongtong-gu, Suwon 443-721, Korea E-mail:mpark@ajou.ac.kr

Received October 14, 2014 / Revised December 12, 2014 / Accepted April 2, 2015 remained to be done, a soaked disposable hand towel was placed over the Dingman mouth gag site. A hole matching the mouth was made on the towel. After making the hole, it was dipped in water again and gently wrung. The hole was placed over the mouth and water was dripped onto the towel surrounding the hole. During suture, this wetting helped keep the towel in place (Figs. 1, 2).

We applied this draping technique over the Dingman mouth gag for every cleft palate surgery from 2012 to 2013. The total number of cases was 26 . The average operation time was reduced to 89 minutes, 14 minutes less than the previous average of 103 minutes in operations from 2010 to 2011. This indicates that cleft surgery was performed under more favorable circumstances.

\section{DISCUSSION}

The Dingman mouth gag is popular in many cleft palate and intraoral surgeries for several reasons. The surgical field of oral surgery is very narrow and deep; hence the gag has played an impor- 


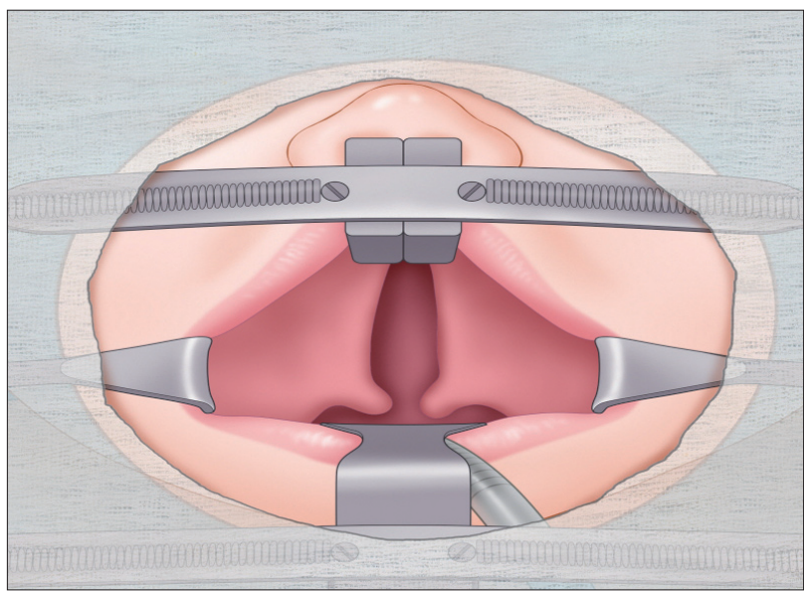

Fig. 1. Schematic illustration. A hole expose patient's mouth fully, and rest of hand towel covers the Dingman mouth gag. The size of hole can be controlled depending on the surgeon's preference.

tant role in opening and maintaining the intraoperatively-opened field. The gag is especially useful when fixed in place for oral surgery. Although many cleft surgeons have tried to create a better environment by modifying the gag, these efforts were limited to improving stability or adding a light source to the retractor itself. Our method is simple but applicable to any modified gag setup [1-5].

There are several advantages to this method. First, it can prevent suture material from being caught in the gag. Repair is the last very important procedure in cleft palate surgery. Long operations lead to surgeon fatigue. A tired surgeon is easily annoyed by small, unimportant events, such as caught suture material. Repetition of these minor incidents results in diminished concentration and poorer results. Second, it may reduce suture material-associated infection. Despite a facial drape on the cleft patient, there is no definite barrier between the aseptic and septic condition. Because the surgeon must focus on repair, the suture material is not given much attention. Prolonged duration of repair increases the possibility of contamination. In addition to aseptic conditions, cleansing suture material becomes much easier. Third, the surgeon can retain focus on the operation field. A simple circular vi-

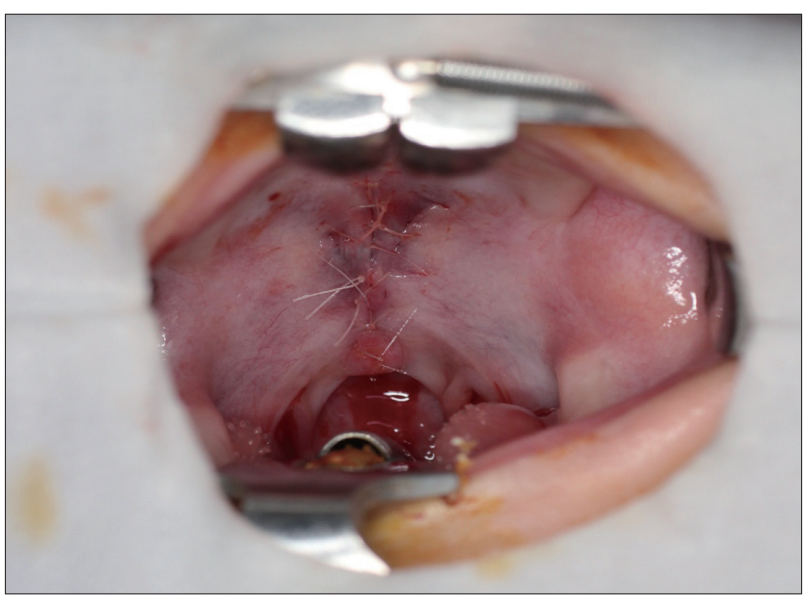

Fig. 2. Operation view. The photograph shows operation field after repair. A hand towel must be immersed with water.

sual field that excludes vision outside the circle facilitates this. Furthermore, warm temperature is essential to pediatric operation. Dripping water on the towel decreases the temperature around the field. The surgeon finds this procedure refreshing.

Cleft palate surgery is a sophisticated operation. It requires the keen ability of a surgeon to focus on the operation. This simple draping compensates for the many disadvantages of this encumbered space. We evaluated the operation time only, but expect that results can also be improved.

\section{REFERENCES}

1. Millard DR Jr, Slepyan DH. Modification of the Dott-Dingman mouth gag. Plast Reconstr Surg 1977;59:593-5.

2. Lehman JA Jr, Burger K. A new light for the Dingman-Millard mouth gag. Plast Reconstr Surg 1985;75:280.

3. Laitung JK. A modification of the Kilner-Dott mouth gag for improving exposure to the nasopharyngeal area. Br J Plast Surg 1986;39:268-9.

4. Gahankari D. Dingman-Grabb's retractor: the other way. A new modification proposed. Plast Reconstr Surg 1996;98:1115-6.

5. Ozdemir A, Karaaltin MV, Guneren E. Modified Dingman mouth retractor. J Craniofac Surg 2012;23:347. 